\title{
El uso de la prensa como medio de transmisión de ideas económicas: El caso de la influencia entre Ramiro de Maeztu y Luis de Olariaga
}

\author{
JESÚS M. ZARATIEGUI \\ Universidad de Navarra, Facultad de CC.EE., Edificio Amigos, Campus Universitario, 31080 \\ Pamplona, España.E-mail: jmzarati@unav.es
}

\begin{abstract}
RESUMEN
Información económica y difusión de ideas a través de artículos de prensa, son dos actividades que los periodistas tienden a confundir en su actividad. Pero son distintas: es la distancia que media entre formar e informar. En este artículo mostramos cómo combina las dos facetas el periodista español Ramiro de Maeztu, especialmente en sus años ingleses como corresponsal de prensa. En su formación tiene un papel decisivo el economista Luis de Olariaga, que le aporta su consejo sobre lecturas y sus contactos en los medios financieros. Maeztu fue algo más que un intelectual al que gustaba escribir artículos de información económica, sino que puede ser considerado un pionero en la difusión de ideas económicas a través de artículos de prensa, que llegaron a un público de clase media muy amplio.
\end{abstract}

Palabras clave: Transmisión de ideas económicas, Ramiro de Maeztu, prensa.

\section{The Press Used as a Vehicle for Transmission of Economic Ideas: The Case of Mutual Influence between Ramiro de Maeztu and Luis de Olariaga}

\begin{abstract}
Economic information and spreading of economic ideas through articles in newspapers are two concepts that maintain certain similarity but are different in essence. It is not the same to form that to inform. Using as an element of contrast the work as a journalist of the Spanish economist Luis Olariaga, in this article we intend to show that Ramiro de Maeztu can be considered a pioneer in the spreading of economic ideas through his articles in newspapers and books. This flow of ideas reached a broader audience than the pure academic world. He chose a different path that the one followed by his colleagues of the "generation of 98 ", so he addressed a lay audience, through his work as a press correspondent in London.
\end{abstract}

Keywords: Spread of Economic Ideas, Ramiro de Maeztu, Articles in Newspapers.

Clasificación JEL: A11, A12, Z11

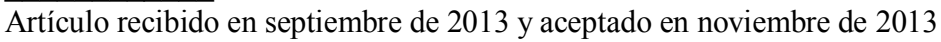

Artículo disponible en versión electrónica en la página www.revista-eea.net, ref. ə-32116 


\section{INTRODUCCIÓN}

La difusión de las ideas económicas se revela como un gran campo de exploración, con diversos niveles de análisis que van desde la comunicación académica entre especialistas hasta la transmisión informal que realiza la prensa o formatos más populares. En la información sobre la crisis económica actual se ha intensificado esta dimensión popular de la diseminación de conceptos económicos. Todos nos hemos acostumbrado a escuchar en conversaciones de calle la opinión sobre la prima de riesgo, el déficit del Estado o las medidas de ajuste fiscal. Han pasado a formar parte del acervo común, no solo de especialistas ¿Cómo han llegado estas nociones, hasta hace poco desconocidas, a estar en los temas de conversación diario? La respuesta es sencilla: a través de vehículos informales de adquisición de conocimientos (prensa, televisión, literatura). Los textos profesionales no llegan al gran público con la profundidad de esos medios alternativos. Esto explica que los economistas prestemos cada vez más atención a los textos literarios y a las obras de arte de contenido económico, con objeto de identificar esos caminos de transmisión de las ideas económicas.

El libro de referencia en esta cuestión es La difusión de las ideas económicas, cuyos editores (Coats y Colander) ofrecen las conclusiones de un ciclo de conferencias celebrado en 1989 en Middlebury College (Vermont). No es una simple recopilación de artículos sino que elaboran un nuevo enfoque sobre los mecanismos de transmisión de las ideas económicas que, en décadas posteriores, ha sido la semilla de innumerables trabajos de investigación. Ellos proponen tres modelos explicativos de cómo esas ideas se diseminan en la sociedad: el modelo de la enfermedad infecciosa, el del mercado de las ideas, y el de la teoría de la información. En el modelo de la enfermedad se trata de establecer los puntos de contacto entre los portadores de la enfermedad y los susceptibles de ser contagiados. El segundo ve el proceso en función de las ideas en un mercado con su oferta y demanda. Este modelo procede del campo de la elección pública (Tullock, 1976). El último aplica la metáfora de las ideas como flujo de información que se transmite a toda la "comunidad", que adopta la forma de "universidad invisible" o "red de personas con ideas afines". Tales redes pueden notarse en la España de la crisis económica pero también podemos rastrearlas hacia atrás en el tiempo. Este es el enfoque que más nos interesa: los medios escritos crean redes invisibles entre los lectores que comparten sus ideas económicas que se han formado, en muchos casos, a través de la lectura de artículos de prensa, y no a través de publicaciones especializadas. El mismo 1989 Peter A. Hall publicó su libro sobre el impacto político de las ideas keynesianas que incidía en un aspecto conexo con el anterior: las ideas (económicas) tienen consecuencias, en este caso políticas. A pesar del aparente interés del tema, es escasa la investigación en torno a la comunicación de acontecimientos e ideas económicas, tanto desde la perspectiva de los medios de comunicación como de 
la recepción pública de los trabajos e investigaciones de los economistas, aunque no han faltado intentos como el de N. T. Gavin (1998) de profundizar sobre la conexión entre los periodistas y sus lectores.

La cuestión era aún más relevante en los inicios del siglo XX cuando la creciente complejidad del análisis económico puso de manifiesto la subsiguiente incapacidad del público en general para comprenderlo. La mayor parte de los periodistas tenían dificultades, si no incapacidad, para hacerse cargo de las complejidades de la ciencia económica, por lo que normalmente recurrían a visiones muy simplistas de la realidad económica. Esto es evidente en la labor de Ramiro de Maeztu como corresponsal de prensa en Londres entre 1905 y 1920 (Zaratiegui, 2006). Hombre de profundas inquietudes, transita desde un socialismo con tintes anarquistas hasta el tradicionalismo en los últimos años de su vida, pasando por una etapa en la que la influencia de Ortega y Gasset y Unamuno le llevan a posiciones cercanas al liberalismo. Durante sus años londinenses entró en contacto con el economista Luis Olariaga, alavés como Maeztu, pronto amigos, e inductor de la creciente afición de Ramiro por las cuestiones económicas, alimentada tal afición por las lecturas que le recomendaba su paisano. Pronto, los artículos que Maeztu envía aparecen trufados de referencias a sindicatos, novedades editoriales en materia económica, o las consecuencias económicas de la paz de Versalles. Pero aportar información económica no significa automáticamente transmitir ideas. Un economista prestigioso como Olariaga puede ser también "un divulgador de los problemas económicos a través de la prensa" (Pérez de Armiñán, 1991: 11). En este artículo intento mostrar que Maeztu hace algo más que informar sobre los temas económicos del momento, sino que forma a sus lectores dándoles las claves para entenderlos. Por eso nos interesa saber cómo fue su formación económica, y qué eco tenían sus crónicas, especialmente en la conformación de un ideal técnico conectado con el tradicionalismo religioso de corte tecnocrático. Mezcla que, relaborada tras la muerte de Maeztu en 1936, será el sustrato ideológico del franquismo. Y que Amando de Miguel (2006: 395) considera "sin duda la aportación más completa de un intelectual a las ideas económicas".

\section{RAMIRO DE MAEZTU EN EL PANORAMA INTELECTUAL Y POLÍTICO DE LA ESPAÑA DE SU ÉPOCA}

El ámbito de estudio que contemplamos puede ser estudiado desde el más genérico de Economía de la cultura aunque, como todos los temas fronterizos entre disciplinas, ha sufrido un proceso de fragmentación y consolidación constante desde sus inicios (Seaman, 2009: 7-32). La difusión de ideas económicas a través de medios auxiliares como el cine, la prensa o la televisión es un fenómeno de los últimos 50 años, pero vemos que mucho antes personajes como Ramiro de Maeztu hicieron lo propio a través de su labor periodística. 
Como en otros aspectos de la cultura (arte, psicología, física) el desencadenante de este proceso fue la transformación radical del papel de los intelectuales que se produjo en torno a la crisis de 1898 , gracias a las nuevas oportunidades que ofrecía la actividad periodística. "La extensión del mercado de la prensa y de los libros, con el consiguiente aumento del número y la difusión de los periódicos y las revistas, permitieron a los nuevos trabajadores del intelecto la subsistencia económica mediante la publicación de artículos, libros o poesías" (González y Robles, 2000: 7-8). Se abría así un campo nuevo que convivía en muchos casos con la actividad académica. Muchos de estos intelectuales procedían de las clases medias, es decir, sectores tradicionalmente apartados del poder, y que tendían hacía el radicalismo social, a veces acompañado de un cierto mesianismo. La familia de Maeztu es un ejemplo: de origen burgués, pero arruinada al quebrar sus negocios cubanos. A esta isla se encaminará un joven Ramiro para dedicarse a leer a los obreros que trabajaban en el azúcar las obras de autores de todas las ideologías, incluso un anarquista como Kropotkin. Maeztu fue pionero en hacer uso de la nueva palabra "intelectual" para reprochar a los socialistas el desprecio que sentían hacia ese colectivo. Será en el Grupo de los tres (Azorín, Baroja, Maeztu), surgido como una de las primeras manifestaciones de la "generación del 98", donde se configura un modelo específico de la idea de intelectual; aunque el grupo perdiera fuerza por el empeño de sus componentes en abarcar demasiados campos a la vez: novela, periodismo, ensayo político y filosófico, poesía. Solo Maeztu rechazará el "arte por el arte", con su dedicación exclusiva al periodismo, y su obsesión por mantener su compromiso sociopolítico, mientras que otros se fueron retirando hacia la pura creación estética (Alsina, 2013: 4-33). Es lo que escribe a su hermana María desde Londres: "Todo orador y todo escritor debe estar siempre a la altura de los menos, aunque sin perder contacto con los más. El contacto con los más lo da la palabra" (ARM, 1910).

En esa posición de divulgador tuvo una influencia decisiva su relación con Ortega y Gasset (él mismo se consideró orteguiano toda su vida), que encauzó esas tempranas inquietudes hacia el campo del compromiso político, aunque el punto de llegada de uno y otro fuera tan dispar. La nueva clase de los intelectuales cubría un espectro amplio de gentes aunque estuviera más vinculado a la literatura, al periodismo y a lo política que a la función docente. Su posición central en la difusión de ideas fue el enlace con las nuevas clases burguesas de comienzos de siglo: era solo cuestión de tiempo que se estableciera una alianza (tácita o explícita) entre ambos grupos para acometer la gran tarea de control ideológico de las masas populares. La urgencia venía del hecho de que las nuevas ideologías (socialismo, comunismo, fascismo) estaban ganándose a los estratos medios e inferiores de las sociedades de todo Occidente. La "rebelión de las masas", en palabras de Ortega, constituía el mayor peligro que se cernía sobre el programa liberal elitista que pretendía la dirección de las masas por una 
élite escogida de hombres, los intelectuales, al servicio de los objetivos de poder de la burguesía.

Los intelectuales tenían un alto concepto de la tarea que tenían de movilizar ideológicamente a la población. A la creencia ciega en un progreso científico y técnico, propia de esos años iniciales del siglo XX, se unía el plano moral, en el que los intelectuales se sentían como el culmen de ese progreso. No eran solamente los que sabian, sino también los depositarios de unos valores que ellos deberían transmitir a sus congéneres. Los tradicionales mecanismos de difusión académica eran incapaces de servir a ese propósito. Las nuevas formulaciones económicas de la teoría neoclásica no podrían llegar al gran público a través de las disertaciones de un Alfred Marshall en su Universidad de Cambridge: tendrían que ser estos nuevos publicistas los que hicieran familiar al lector conceptos de difícil comprensión por su contenido matemático o técnico. Esta clase de influencia presuponía, casi de forma implícita la actividad política. El intelectual debía estar "comprometido", no podía ser un mero erudito, su vida misma tenía que ser un ejemplo de lo que intentaba transmitir. Ese compromiso se entendía que era con las nuevas ideologías emergentes de izquierdas. Incluso un Maeztu que acabará en la derecha más reaccionaria, comenzó su labor comprometido con la difusión de autores anarquistas y socialistas; y acabó muriendo por su compromiso con las ideas opuestas de las que tuvo en los primeros escarceos políticos. Aunque, por antonomasia, el compromiso era con las izquierdas.

El carácter genuino de esa inclusión en el campo de la izquierda es tema de amplio debate. Una adhesión a los postulados de la lucha de clases preconizada por el socialismo español, era incompatible con la presencia dentro del PSOE de intelectuales, a los que aquellos consideraban burgueses camuflados para beneficiarse de las ventajas de poder usar la marca "socialista". De ahí que predominara entre los intelectuales lo que Alsina llama una alineación "situacionista" con la izquierda, en la que primaban valores como el inconformismo o la crítica a lo establecido. Maeztu es un ejemplo de ese situarse en la izquierda crítica sin serlo del todo, algo que Olariaga censuró en diversas ocasiones. Genuina o táctica, en todo caso tal posición abría un amplio campo a la difusión de ideas económicas a los obreros a través de los artículos periodísticos. Es interesante comparar las diversas versiones del mismo artículo que Ramiro enviaba a los distintos medios en los que publicaba, en función de sus lectores. La rápida referencia a un concepto económico que aparecía en su artículo para un diario culto como $\mathrm{El} \mathrm{Sol}$, merecía una redacción más detallada con ejemplos concretos cuando, a veces en el mismo día, salía publicado en La Correspondencia de España o La Nación. Los mismos editores guiaban el trabajo del corresponsal señalando el tono excesivamente teórico o divulgativo en cada caso, para dirigir en esa dirección las futuras colaboraciones. Las ideas debían llegar en el envase adecuado a cada público. 
Aunque tuvo diversos ofrecimientos, Maeztu insistió en dedicarse a los periódicos de gran difusión y se niega a "subir al plano de Ortega" (AEA.15.7.08), es decir, a las publicaciones académicas. Todo lo que aumente las responsabilidades de la prensa, dice, aumentará su prestigio, porque la gente creerá en lo que decimos y acabará por conferirnos el poder que nos corresponda. Trabaja en solitario: más en los periódicos y libros que en la información directa; sólo le interesan los temas de otros países en la medida en que afecten a España. No le interesan los temas abstractos, deben ofrecer remedios para los males que aquejaban a nuestro país. En carta a su hermana María, que era discípula de Ortega, Ramiro hace una "comparación con Pepe [Ortega]. Pepe es un profesor. Ese es su oficio. Yo no lo soy, ni quiero serlo, porque no está en mi vocación. Podré ser (...) un agitador de ideas, por deber hacia España (...) En sí mismas, no me interesan las teorías. Las teorías para mí son instrumentos de trabajo (...) Lo que me interesa es escribir, divulgar las ideas" (ARM, 13.8.11). La acción que desarrolla en la prensa sobrepasa con mucho la simple divulgación.

Una característica que unifica a la generación del 98 es precisamente este carácter reivindicativo de una España mejor, aún no es la España Eterna que invocará Maeztu y otros autores, abriendo las puertas a la dictadura y al franquismo. Pero ese inconformismo que inicialmente les acerca al socialismo pronto cederá terreno a una actitud más pragmática, de crítica puramente académica, inofensiva, que llega solo a las élites, y ante la que Maeztu reacciona con horror ya que no entiende otro modo de vivir que no sea comprometiendo la propia pluma y la propia vida en aquello en lo que se cree. Otra cosa es que ese planteamiento también tenga abundantes ribetes utópicos. Por eso, sorprende cuando Laín excluya a nuestro polígrafo del núcleo duro de la generación del 98 que, en su opinión, la formaban Unamuno, Azorín, Baroja, Machado y Valle-Inclán. Solo dos del Grupo de los tres. El "amor de amargor" (AEA.25.6.08) que unificaría a sus integrantes acaba discurriendo no por los cauces de la acción publicística o política sino por la literatura del ensueño. Un extraño amargor que les lleva a cohonestar con el régimen político del momento, a cambiar de bandera cuantas veces sean necesarias, y a vivir de ser artistas. Sorprendente porque, con la excepción de Unamuno, solo Maeztu llevará hasta sus últimas consecuencias las consecuencias de sentir hondo ese amargor por los males de España.

\section{EL INFLUJO DE OLARIAGA EN LA FORMACIÓN ECONÓMICA DE MAEZTU}

La formación económica de Ramiro cuando marcha a su corresponsalía londinense en 1905 era escasa pero progresivamente sus artículos revelan una presencia mayor de contenido económico (noticias, comentarios, glosas de libros publicados). En esta progresiva formación y familiaridad con esa área del conocimiento, tiene mucho que ver su amigo y paisano, el economista Luis de Ola- 
riaga. Aunque era once años más joven que Ramiro, éste supo ver muy pronto las grandes cualidades del que sería maestro de economistas y uno de los impulsores de la primera facultad de ciencias económicas, la de Madrid, nacida en 1943. Hombres como Lucas Beltrán, Sardá, Castañeda, Velarde y tantos otros pueden considerarse discípulos del pensador vitoriano, liberal y católico.

Luis de Olariaga (1885-1976) llegó a Londres en 1908, tres años más tarde que Maeztu, para estudiar el sistema bancario inglés. La Inglaterra eduardiana vivía años de decadente esplendor, tras casi dos siglos de indiscutido dominio mundial. Los síntomas de decadencia de la clase empresarial británica ya estaban ahí, $y$, de hecho, en términos de producción nacional había sido sobrepasada por los Estados Unidos y Alemania (Zaratiegui, 1996). A pesar de ello, Inglaterra seguía siendo el centro de referencia mundial en teoría económica. El liderazgo de la economía neoclásica, a partir de Alfred Marshall, no se veía aún contestado por su joven discípulo John M. Keynes, que ya apuntaba en sus escritos a un mayor protagonismo del sector estatal sobre el privado, que la I Guerra potenciaría al poner toda la industria nacional al servicio de las necesidades de la guerra, y bajo el control de los burócratas de la Administración. La City seguía atrayendo capitales y el sistema bancario privado y el Banco de Inglaterra eran el modelo en que se miraban todos los países que pretendían ordenar su sistema financiero. Alemania no era aún el país de las botas altas sino el de la cultura y el arte. El encuentro entre Maeztu y Olariaga en Londres es el de maestro y discípulo. Maeztu era un articulista muy conocido en el ámbito hispánico. Olariaga, con apenas 21 años, sin estudios universitarios, llegaba para trabajar en el banco Crédit Lyonnais.

Olariaga, hijo de la pequeña burguesía alavesa, se empleó muy joven en la banca. Sus inquietudes intelectuales le llevaron a Londres a trabajar en la filial de ese banco francés, y pronto se puso en contacto con Ramiro de Maeztu, corresponsal entonces de diversos periódicos españoles y argentinos. Éste le introdujo en el sugestivo mundo del socialismo anglosajón de comienzos de siglo y le presentó a José Ortega y Gasset, quien le animó a seguir estudios universitarios. Luis se inclinó por los estudios jurídicos que cursó en varias universidades españolas desde 1909. Tomando como punto de partida su experiencia comercial y bancaria empezó a cultivar la Economía Política. Una pensión de la Junta para Ampliación de Estudios le permitió una estancia de dos años en Berlín para estudiar con los economistas Wagner, Sering y Oppenheimer. Pero mantiene estrechos lazos con la escuela de Cambridge, como muestra el paralelo de opiniones mantenido por Olariaga y Keynes a lo largo de la década de los veinte sobre las consecuencias de la primera guerra, las reparaciones y la política monetaria (Almenar, en Fuentes, 2008, II: 55). Así los primeros pasos en la cosmopolita Londres los dio Olariaga de la mano de su mentor y amigo Maeztu. Es él quien le aconseja sobre lecturas. 
Este Maeztu londinense encaja muy poco con la proyección pública de sus últimos años, imagen que persistirá como la del auténtico Maeztu cuando en los años cuarenta el grupo de tradicionalistas católicos se apropie de su legado. Siempre irritó a Olariaga el aprovechamiento partidista de la gigantesca personalidad de aquel vasco al que consideraba como su hermano mayor y que tanto influyó en tantos hombres de su generación (Pérez de Armiñán, en Fuentes, 1999, VIII: 523). Maeztu le prestó los primeros libros de economía y le sugirió que hiciera en España la carrera de derecho. De Miguel (en Perdices, 2006: 395) aporta una explicación complementaria: que Laín Entralgo en el clásico estudio sobre esa generación intelectual (España como problema) apenas destaque el pensamiento del vasco. Esto se pone en relación con el enfrentamiento de Laín con el grupo de católicos tradicionalistas que habían hecho bandera de la obra de Maeztu.

Ramiro pone a Olariaga en contacto con las teorías político-sociales corporativistas en boga (guildistas y fabianas), y encauza sus intereses desde el mundo bancario a la teoría monetaria (Fuentes, 2008, II: 193). De ahí surgió en él un interés que mantendrá toda su vida en la política social liberal de raíces germánicas. De hecho, tras completar sus estudios de Derecho, animado por Ortega y Unamuno (a quienes había puesto en contacto Maeztu) fue a Alemania donde conoció los principales debates económicos y sociales (Sozialpolitik, Methodenstreit). Sumado todo ello a las enseñanzas técnicas de Flores de Lemus, quedará marcada la dirección social última de su teoría económica.

Otra nueva conexión con Olariaga la encontramos a través de Joaquín Sánchez de Toca (1852-1942), político y hacendista conservador, ministro de Hacienda en dos ocasiones. Destaca Maeztu el empeño de Toca para que el país tome conciencia de la urgencia de enterrar la nostalgia del Imperio y de construir una sociedad moderna; la pérdida de las colonias, desde su punto de vista, debía considerarse como una ventaja; Maeztu usa La industria nacional y la Comisión protectora de las industrias nacionales (NM.18.5.17) donde defiende que la industria y la agricultura españolas salen ganando con la guerra. Las potencias vencedoras convocaron en abril de 1922 una conferencia en Génova para revisar el cumplimiento por Alemania de las reparaciones de guerra estipuladas al acabar la guerra. Expertos de países no beligerantes fueron invitados para aportar sus expertos. También España envió una comisión presidida por Sánchez de Toca, entonces Presidente del Senado, y de la que formaba parte Olariaga como Secretario y asesor económico de la delegación española (Pérez de Armiñán, 1991: 104-107). Olariaga enviará sus artículos al diario El Sol y por ellos sabemos que sus puntos de vista están muy cercanos a los que había mantenido Keynes en Las consecuencias económicas de la paz donde ya había afirmado el autor que era indispensable revisar el Tratado de Versalles, ya que "al quebrar la vitalidad industrial de Alemania acabaría por producir durante la paz más estragos que la guerra". Un artículo de Olariaga titulado "El econo- 
mista inglés demuestra que Alemania no puede pagar las reparaciones" (S.15.02.22) resume bien sus puntos de vista al respecto.

La relación se mantiene como se comprueba por la reseña (19.11.26) que hace Maeztu de un artículo de Olariaga en El Sol sobre el puritano capitalismo americano, aunque no entra en valoraciones morales. Únicamente establece la relación entre el capitalismo y la gran industria que América habría recibido de Inglaterra. Ramiro piensa también (23.11.26) que el desarrollo del espíritu capitalista viene con la gran industria. También son deudoras en buen parte de Maeztu las ideas que Olariaga expresa en su libro La des-espiritualización de la sociedad moderna (1928).

Como apunta Fernández (2008: 24-34) la herencia teórica y práctica de Olariaga, pensador liberal y católico, se rastrea decisivamente en la historia reciente de la ciencia económica española, en los planes de desarrollo y estabilización desplegados por el régimen franquista durante los años sesenta, en la difusión del pensamiento económico liberal de las Escuelas de Friburgo (Eucken, Müller-Armack, Röpke) y de Viena (Hayek, Menger, Mises), y en el debate neo-keynesiano, del que fue pionero introductor en nuestro país. Que Maeztu recibió el influjo de la economía social de mercado alemana, puede advertirse en la correspondencia que mantuvieron durante años los dos alaveses; y los argumentos de los artículos que publica revela una familiaridad con estos autores, siquiera sea por medio de lecturas apresuradas para dar cuenta de las nuevas corrientes económicas europeas. Es importante destacar por qué Olariaga influye tanto en Ramiro: porque el primero no es teórico (a Maeztu no le interesaban) sino un hombre práctico que ponía su saber económico al servicio de otras causas. Lo percibe bien Cepeda (2003) cuando advierte que este profesor y consejero "no era un buen conocedor de la Teoría económica"; así, "la aportación de Olariaga no es destacable como contribución teórica, sino como economista político con un cierto compromiso por el desarrollo de su país; como hombre clave en la modernización de las prácticas bancarias españolas, en la formación de nuevas generaciones de economistas y como consejero en la alta política". Es una faceta peor conocida de su personalidad su compleja reflexión político-social, desplegada tanto bajo la monarquía de la reforma social alfonsina y la dictadura de Primo de Rivera, como bajo la II República y la dictadura estatista del general Franco.

Un último aspecto de la influencia de Olariaga en Maeztu. Cuenta Velarde Fuertes (1968) que José Antonio Primo de Rivera preparaba su tesis doctoral, bajo la dirección de Olariaga, sobre el movimiento guildista de raíz socialista, en la Inglaterra de comienzos de siglo (el dato se lo habrían facilitado Ramón Serrano Suñer y Pilar Primo de Rivera). Pues bien, los dos inspiradores del movimiento, Eliot y T. E. Hulme, eran amigos de Maeztu que durante algún tiempo coqueteó con esa corriente, antes de conocer el fabiano. Olariaga, a través de 
Maeztu, estuvo muy enlazado durante su estancia en Londres con este movimiento, y tenía trato cordial con Keynes. De esta tesis iniciada con Olariaga, en torno a otro debate entre sindicalismo y socialismo, ¿procederán las búsquedas de José Antonio de enlaces con la CNT y sus aledaños?, se pregunta Velarde. Quizá sea así.

\section{MAEZTU, UN PERIODISTA QUE INFLUYE (DIVULGA) CON SUS ARTÍCULOS}

Ramiro de Maeztu fue toda un vida un periodista por encima de su adscripción a otras categorías como las de intelectual, pensador o filósofo. Solo así se entiende su papel como divulgador de ideas económicas. La calificación como pensador es muy tardía y corresponde al grupo de católicos tradicionalistas que enarbolaron la bandera de Maeztu para defender sus ideas en la posguerra española. Salvo su breve estancia en Argentina como embajador Ramiro no hace otra cosa que escribir artículos de prensa. Todos los libros son recopilaciones ordenadas y retocadas del material que le proporcionaba su ingente labor periodística. Incluso fueron artículos sus conferencias, algunas de sus poesías, y la novela "La guerra de Transvaal" por entregas.

No es posible encontrar entre sus contemporáneos una producción tan abundante: casi 5000 artículos de prensa, en 60 revistas y periódicos diferentes sobre los temas más dispares. Mientras que para Azorín, Unamuno e incluso Ortega el periodismo era una actividad ocasional, complementaria de la intelectual, para Maeztu es un medio de vida. A veces se queja de la falta de reflexión que conlleva tal estilo de escribir (AEA.24.1.04), con la consiguiente falta de profundidad de pensamiento (AE.10.34). Sus paralelos podrían ser personajes como Luis Araquistaín, Manuel Bueno, Corpus Barga o Francisco Granmontagne.

Las dos notas características del escritor vasco que aspira como publicista a influir en sus lectores, a crear estados de opinión, nos hablan de un periodismo intelectual y político. Por eso utiliza un estilo vulgarizador, intermedio entre los modelos teóricos y el hombre de la calle. "Los periodistas españoles no hemos reparado en que a la prensa corresponde, si no la dirección suprema de los pueblos, función de los creadores de ideas, de los intelectuales puros, abstractos, andrógenos, al menos la orientación inmediata de la vida colectiva, mediante la transformación de los productos ideológicos del intelectualismo, en ideales eficientes, carne y sangre de un pueblo" (HOE: 83).

En cuanto periodista, Maeztu fue consciente de su capacidad vulgarizadora que ejerció siguiendo un criterio y unos objetivos bien definidos. Este era el fondo de la polémica que sostuvo con Ortega que intenta capta al vasco para la "alta cultura". Maeztu pone su habilidad periodística al servicio de Ortega no sin protestar contra el menosprecio de éste hacia "el periodismo como escuela mental". Al día siguiente le explica por qué prefiere escribir para el gran público 
en los periódicos de mayor tirada: "No quiero hablar como Costa, desde el Sinaí" (Ortega, Epistolario, cartas 14 y 15.7.08). Ortega acusa al vasco de querer que todos sean periodistas divulgadores. "No admite usted la posibilidad simultánea de que sea necesario para España que usted sea periodista y que yo no lo sea". Maeztu reconoce la necesidad de la ciencia pura, pero él ha escogido la divulgación de la "cultura utilitaria", aunque "ha tenido ya tres o cuatro oportunidades de dejar este trabajo vulgarizador de los periódicos y consagrarse exclusivamente a investigaciones de alta cultura" (NM.30.7.08). Los ejemplos que aduce de cultura utilitaria frente a la alta cultura (escuelas, sanidad, transportes, seguridad) entran más en el campo del desarrollo que de la cultura propiamente dicha y le sitúan en las coordenadas del regeneracionismo costiano. Insiste en el carácter divulgador de su periodismo que como el de Unamuno y Grandmontagne ha tenido efectos más amplios y reales que los minoritarios del krausismo (RO.30.9.08). Consecuente con sus criterios de divulgación roba sin remordimiento pensamientos a Ortega y al experto del momento "porque para eso se piensa para que lo roben los demás" (C.10.10.09). Cuando en 1909 abandona La Correspondencia explica su paso al Heraldo en la colaboración para organizar las izquierdas, tarea a la que debe contribuir con su "pluma de periodista" y su "cerebro de vulgarizador" (C.10.12.09). La mejor definición de este tipo de periodismo más difusor que reflexivo nos lo da en 1914: "yo no renuncio a nada. Yo soy un periodista. Un periodista es un centinela que da el quién vive, a cuantos problemas le pasan por delante" (NM.19.3.14)

Algo que explica el éxito divulgador del escritor vasco es su capacidad de expresar ideas generales en términos sencillos. Crea un estilo ágil y directo que se adaptaba perfectamente a sus propósitos divulgadores. Es el estilo que lleva a su madurez en los años ingleses, después de años en los que había sabido "escribir corto e intenso", dice a Ortega en carta de 21 de abril de 1915. En parte, ese estilo doctrinal y pesado de sus primeros años se debía al hecho de que aún abrigaba ambiciones literarias: prueba de ello son las poesías, obras de teatro y cuentos que escribió en esos años. Pero siempre hizo que la sencillez se convirtiera en simplificación, buscando la cercanía con el lector medio. Probó sin éxito a aconsejar a Ortega para que hiciera lo mismo: "si no se escribe de tal forma que se engañe al lector persuadiéndole de que sabe tanto como el que escribe, entonces no hay lector, porque el español es poco dócil para aceptar la superioridad intelectual" (RO.2.7.08).

Maeztu llega a Inglaterra en un momento en que los medios de comunicación dedicaban cada vez más atención a la actualidad económica, lo que ha permitió que se consolidase, dentro de las especializaciones periodísticas, la del periodismo económico. El cambio se había producido con el comienzo del siglo XX. Tras la revolución marginalista de los años setenta y la aparición de la figura del economista académico, con Alfred Marshall como uno de sus arquetipos, la ciencia económica empieza su verdadero desarrollo. Y con él da 
comienzo su "alejamiento" de la actualidad, al menos de la actualidad manejable desde los medios de comunicación. El propio Marshall, en 1885, con motivo de su lección inaugural en la Universidad de Cambridge, comentaría que la profesionalización de la disciplina haría desaparecer a los "contadores de fábulas económicas". Sin duda, muchos de ellos escribían en los periódicos (Arrese, 2000: 313). Con el fin de siglo acababa la edad de oro del que, con Stigler, podríamos definir como "economista predicador". Los economistas se encerraron poco a poco entre los muros metodológicos de su disciplina. Pero eso abría la puerta a periodista como Maeztu que conocían algo del mundo económico y ocuparon los lugares que abandonaban los economistas profesionales. Esto no se correspondió con cambios significativos en la formación de los profesionales, con lo que en muchos ámbitos informativos la función del periodista no iba más allá del mero registro de los acontecimientos noticiosos y de la reproducción acrítica de la opinión de los expertos.

Un modelo que muchos periodistas imitaron fue el de John Maynard Keynes, cuyas reformulaciones de la teoría económica no sólo calaron en la comunidad académica, sino que fueron aireadas por sus autores a través de una destacada actividad de divulgación en la prensa. Es de destacar, en este sentido, la extraordinaria difusión de las ideas de Keynes, verdadero personaje público y economista paradigmático de este siglo, cuyos planteamientos teóricos dominaron la política económica de los países occidentales tras la II Guerra Mundial. Pero que ya en el primer tercio del siglo ejercía una notable influencia en los informadores ingleses. Maeztu acude a su autoridad y a sus artículos sobre todo en la etapa posterior al final de la I Guerra Mundial, cuando Keynes advertía de las "consecuencias económicas de la paz". No sorprende que, ante esta situación, para dirigirse al público en general, los medios de comunicación recurrieran a la colaboración de supuestos "expertos", capaces de ofrecer explicaciones simplificadas de la realidad, antes que acudir a verdaderos especialistas, en general incapaces de transmitir con sencillez las implicaciones de su investigación. Se puede quedar así a expensas de la divulgación de ideas y visiones, poco ortodoxas, pero al menos comprensible.

Que Maeztu es un difusor de ideas económicas, no un simple informador, lo señala Amando de Miguel (en Perdices, 2006: 398-399) cuando discute la afirmación de Villacañas (2000: 263) de que las tesis del vasco serían "estrictamente weberianas". Max Weber había publicado su libro La ética protestante y el espiritu del capitalismo en 1905 pero Maeztu lo que hace es descartar la centralidad del factor protestante, mientras resalta la mentalidad de ciertos grupos católicos, movidos por una concepción empresarial del dinero. De Miguel cree que una influencia más segura es la de Richard H. Tawney en su obra La religión y el ascenso del capitalismo (1926). Maeztu conocía al profesor de historia económica en LSE, ideólogo del laborismo y candidato político, porque ambos frecuentaban los círculos fabianos, y, de hecho, lo menciona en uno de sus ar- 
tículos (LN.21.4.27). Lo interesante es que nuestro hombre introduce su concepto del "sentido reverencial del dinero" en marzo de 1926, el mismo año de la publicación del libro de Tawney, y su argumentación está mucho más en su línea de un origen del capitalismo con cierta independencia de la teología protestante. La crítica del consumismo, tan frecuente en Maeztu en la década de los felices años veinte, llega tras la publicación por el profesor de LSE en 1920 de La sociedad adquisitiva. De este modo llegaron a nuestro país estas ideas, entonces solo accesibles a un grupo selecto de intelectuales.

\section{LOS MECANISMOS DE TRANSMISIÓN DE IDEAS ECONÓMICAS}

\subsection{Marco metodológico}

El flujo internacional del análisis económico es, como ha señalado E. Lluch (en Fuentes, 1999, I: 435-476), extremadamente complejo por lo que es necesario concretar el marco metodológico en el que nos movemos, para dar algún sentido al proceso de transmisión de ideas económicas. En el autor y la época que nos ocupa existen lo que Hutchison ha llamado "muros" nacionales que limitan el conocimiento de lo que se hace fuera de las fronteras nacionales o culturales. La España del primer tercio del siglo XX apenas tenía contacto con la producción científica europea, si exceptuamos el nexo relativamente fluido con Alemania y el historicismo económico entonces allí dominante. Como venimos mostrando en los casos de Maeztu y Olariaga, es la estancia en Londres la que facilita la ruptura de ese muro: así, una parte de las nuevas ideas tanto neoclásicas como de corte keynesiano serán conocidas en España a través de sus artículos. El efecto es inmediato pues pronto deja de ser el único corresponsal de prensa en la capital británica.

Para el caso español, Lluch se decanta por la tipología de A. Gerschenkron (1970: 198) del atraso en el desarrollo económico como método de análisis. En un regeneracionista como Maeztu este será el argumento que recorra todos sus escritos, ya que considera a la ideología como una de las variables para establecer el grado de atraso y sus repercusiones en la tipología industrial del país. Conecta así el desastre -también económico- del 98 con una característica cultural del ser español, que se encontraría en el polo opuesto de lo que él observa en Inglaterra, Alemania, y años después, en los Estados Unidos. Califica el atraso español como un problema de actitudes colectivas y no de recursos: "como todas las naciones viejas, España tiene abundancia de capitales, pero capitales improductivos". No faltaba dinero, pero sí capacidad e iniciativa empresarial. Su inquietud por el atraso económico de España respecto a Inglaterra coincide con lo que en ese momento preocupaba en las islas en relación al crecimiento industrial de Alemania y Estados Unidos. Estudios como el de Fuentes y Sánchez (2010: 1-28) abordan el emprendimiento, como motor de la innova- 
ción y el crecimiento, desde una perspectiva de género, y encuentran que las mujeres muestran una menor iniciativa emprendedora y un temor mayor al fracaso como freno de la actividad emprendedora. Ha sido el mismo Gerschenkron (1970: 34-41) quien ha desarrollado su propia metodología en un apartado dedicado a la "ideología de las industrializaciones tardías", que él aplica a los casos alemán y ruso. El criterio del atraso económico como principio interpretativo explica "el gran interés por España de grandes economistas, lo que aún no ha sido estudiado sistemáticamente" (Lluch, en Fuentes, 1999, I: 446). Lamentablemente, lo que ya ha sido estudiado en el caso de los escolásticos de la Escuela de Salamanca, por ejemplo, aún está por hacer para los dos últimos siglos de nuestra historia.

Este es el enfoque que adopta nuestro hombre en su análisis de los problemas económicos españoles a la luz de la realidad industrial y económica de la Inglaterra de comienzos del siglo XX. Sin embargo, hay un peligro evidente cuando comparamos, como hemos hecho en el capítulo anterior, a dos personajes como Olariaga y Maeztu y las influencias mutuas que de esa relación se derivaron. Porque uno es un economista aficionado a escribir en prensa, y el otro un intelectual que se gana la vida de forma profesional escribiendo en la prensa. Ese dato debería hacernos muy precavidos a la hora de establecer comparaciones. En ese sentido, Olariaga tiene un gran parecido con Keynes cuyo libro sobre las Consecuencias económicas de la paz apareció en forma de artículos en el Evening Standard, al estilo de lo que haría Olariaga en El Sol sobre cuestiones ferroviarias o hulleras, luego recogidas en libros. También La rebelión de las masas de Ortega aparece en una serie de artículos en El Sol. Que los artículos de Maeztu aparecieron luego recopilados en libros no le hace pertenecer a la categoría de economistas aficionados a la prensa. Es obvio que detrás de los artículos de Olariaga hay todo un entramado doctrinal que intenta transmitir, algo que es más superficial en Maeztu cuyo dominio de la herramienta económica es precario. Pero eso no justifica calificar sus artículos de simple información económica porque haya algo más que nos permite hablar de transmisión de ideas.

Esto no debería llevar demasiado lejos la actividad periodística de Maeztu en temas económicos. Es una labor didáctica, divulgativa, sobre todo. En sus crónicas, intenta dar sentido a la Economía en la vida diaria de las personas, más allá de su ámbito propio, como ciencia de los medios, poniéndola en relación con fines humanos y sociales. Aunque esto tiene sus limitaciones porque si los profesionales del periodismo no asumen la función didáctica, desde un conocimiento sólido, que tiene la información de actualidad sobre temas económicos, se puede estar siendo utilizado para difundir visiones interesadas de la realidad, que poco o nada tienen que ver con las verdaderas necesidades de información de la ciudadanía. La complejidad es la primera barrera que dificulta la cobertura periodística de la economía, máxime si se tiene en cuenta que los asuntos eco- 
nómicos afectan diariamente a la vida de las personas, y casi cualquiera se atreve a hacer juicios de "sentido común" al respecto. Ya comentaba Keynes que "la economía es un asunto difícil y técnico, aunque nadie se lo crea".

Es significativo cómo va guiando a sus lectores para que entiendan las claves explicativas de la crisis financiera de 1907 en los Estados Unidos. El Tesoro se vio forzado a rescatar, junto a un grupo de bancos capitaneados por Joseph P. Morgan, el sistema financiero de su inminente colapso. Maeztu da las primeras noticias advirtiendo de su gravedad: no se trata de un simple episodio especulativo (C.23.3.07) sino resultado de un sistema de crédito descentralizado. La crisis tuvo como consecuencia la creación seis años más tarde de la Reserva Federal. El llamado pánico de 1907 lo provocó la retirada masiva de dinero y consiguiente quiebra de un tipo de banco sometido a poca reglamentación que, con el nombre de trust, desarrollaba actividades de fideicomiso (herencias, legados, etc.). El equivalente actual serían los hedge funds o fondos de inversión libre. Tienen en común el recurrir a un endeudamiento muy alto, amplificando así la magnitud tanto de las ganancias como de las pérdidas resultado de sus inversiones. Tienen mucho que ver con el origen de la crisis actual que, curiosamente, comenzó con una exactitud de reloj cien años después (2007). Los hedge funds ahora, como los trusts en 1907, son entidades poco reguladas, con domicilio, en muchos casos, en paraísos fiscales y a resguardo de la supervisión oficial. Maeztu tranquiliza a los inversores españoles (C.30.10.07) porque entiende que la crisis quedará circunscrita a los Estados Unidos y no afectará a Europa. Otra consecuencia, que él describe 10 años después, será el cambio en 1917 de las condiciones de reserva en los depósitos bancarios. Aunque, para entonces, ya tiene el amplio bagaje que ha adquirido en su relación con Olariaga.

\subsection{Sistematización de los medios empleados por Maeztu para transmitir sus ideas}

El dato de partida es que Maeztu sabía poca economía cuando marchó a Londres en 1905. Conocía el mundo industrial vasco en el que dio sus primeros pasos periodísticos en la prensa bilbaína, pero pronto marchó a Madrid y el tono de sus artículos se vuelve más político. Aunque en 1891 marcha el joven Ramiro para un aprendizaje mercantil a París, donde vivía parte de la familia materna. Sea lo que hiciera allí, la experiencia parisina le convence de que lo suyo no son las finanzas: de "demasiado soñador para el comercio", lo califica Olariaga. Fue con el propósito de dedicarse a comerciante pero se dedicó a escribir. Tiene que marchar a Cuba para hacerse cargo de la administración del ingenio azucarero familiar. A su vuelta, se integra en el mundo periodístico bilbaíno y madrileño.

La época madrileña es de maduración. Forma el grupo de los tres que se da a 
conocer con un manifiesto de tono regeneracionista que contará con el apoyo de Unamuno aunque éste les advierte que "ni entiendo de enseñanza agrícola nómada, ni de ligas de labradores, cooperativas de obreros campesinos, cajas de crédito agrícola y pantanos, ni creo que sea eso lo más necesario para modificar la situación económica y moral de nuestro pueblo" (Marrero, 1955: 66). Maura les responde con un "ya maduraréis". El contenido del programa estaba inspirado en las ideas de Costa y su Liga Nacional de Productores, por lo que el vasco puede ser considerado un regeneracionista. La indiferencia general con que son acogidas sus reivindicaciones sociales, les hace desistir en parte de la acción directa, pero continúa en el periodismo. Aquí se produce la bifurcación entre los hombres del 98 (Azorín y Baroja) que se dedicarán a la especulación estética sobre la ruina del país, y los hombres de acción, como Maeztu, que combinarán siempre la pluma y la espada.

La correspondencia con su hermana María, pedagoga y futura directora de la Residencia de señoritas en Madrid, aporta pistas de cómo se forma Ramiro. En carta de 1896 se permite dar un "consejo intelectual" a su hermana que acaba de cumplir 16 años: "Lee mucho, mucho, todo cuanto puedas, libros, cuantos te vengan a la mano (...) Lee también periódicos. Ellos, malos y todo como son en España, ensanchan la vida, por ellos se vive, además de en la casa, en el mundo" (ARM.7.1886). A pesar de su pobreza de espíritu y de ideas, al menos le servirán para percatarse de la pobre vida espiritual de España. Añade: "Lee Germinal, botella que al mar de la multitud arroja la juventud española, confiando en que el mar ha de llevarla a puerto". Y, por encima de todo, le aconseja que ejerza "siempre el espíritu de crítica, sobre tus ideas y sobre las de los libros, no te dejes llevar por éstas de buenas a primeras, pero desconfía también de ti misma y disponte a modificar tus juicios siempre que de su certeza tengas dudas". Dos años más tarde, alardea de su "salvaje independencia de criterio, que es su condición primordial [la de los espíritus superiores]", porque el precio que cuesta el saber "es una absoluta sinceridad para con uno mismo y para con los demás" (ARM.8.8.98). Ese es el camino para influir: "¡Y tú no sabes la influencia de que gozan en los centros oficiales de la Corte los escritores de nota!". En 1911 refiere a su hermana los esfuerzos que hace por entender a Kant y Hegel, y le sugiere el siguiente "Plan: $1^{\circ}$ estudiar y aprender; $2^{\circ}$ enseñar a los demás. Más para estudiar hay que centrarse. Agarra un libro, uno, cualquiera, clásico. Estrújalo, métetelo dentro, sírvete de los otros libros como auxiliares. Saldrás de ese libro con una barra de acero en el espíritu. Los demás libros que te interesen te los asimilarás con relativa facilidad, por comparación" (ARM.6.8.11).

\subsubsection{Fuentes de donde obtiene sus informaciones}

Las fuentes con las que se forma Maeztu en temas económico ofrecen una 
gran variedad que procede de sus lecturas, noticias recogidas de sus contactos o de otros corresponsales en Londres, y de la prensa de la capital. Él mismo se presenta como un periodista autodidacta: "la prensa me da básicamente los hechos; los libros de ciencia e historia me permiten interpretarlos; los clásicos me proporcionan los valores con que contrastar los datos; y una o dos novelas al año" (E.11.6.15). Concluye: "los periodistas formamos nuestra cultura como buenamente podemos, leyendo los libros que caen en nuestras manos; la educación sistemática y ordenada nos es imposible" (NM.16.4.14). Con frecuencia recoge citas, opiniones, o resúmenes sin precisar su origen (Zaratiegui, 2006). Olariaga (1974: 49-50) dirá que Maeztu "fue ante todo un periodista y vivió de escribir para periódicos, de tener que escudriñar diariamente la actualidad en todos los aspectos y contar al público sus impresiones circunstanciales, aunque atañeran a los problemas más graves de la cultura, de la política o de la vida social puesto que no fue nunca simple informador. Ello le llevó en todas las etapas de su existencia a tener que exteriorizar deprisa y sin el necesario sedimento lo que iba pasando por su mente".

La fuente principal de inspiración es la prensa diaria. En sus artículos aparecen citados un centenar de periódicos y revistas europeas y americanas. Entre los primeros, además de la prensa inglesa, destaca el gran número de publicaciones francesas, alemanas e italianas, pero los hay rusos, nórdicos, incluso egipcias. Apenas encontramos un artículo suyo donde no mencione otra publicación. Maeztu busca en la prensa "los juicios formulados por los expertos" de los cuales "se limita a hacerse eco" (H.6.11.12). Muchos criticaron esa proclividad al uso de nombres de filósofos, científicos, políticos y periodistas en sus artículos. Intenta "ser cuerda tendida en la ventana, para que en ella vibre el viento de la calle" (LPB.10.7.32), donde pueda encontrar eco toda novedad o teoría.

Sobre todo en su etapa inglesa, recurre a sus contactos en la City. Los dos centros de influencia en el mundo son "la City de Londres y las universidades alemanas" (NM.8.5.13). Ramiro acude con frecuencia a sus contactos, sobre todo a Olariaga (1974: 54) que "trabaja en un banco de la City" (el Crédit Lyonnais). Así se entera de la confusión que causa la subida del tipo de interés al $6 \%$ por la salida especulativa de capital inglés hacia la compra de tierras en Egipto y Argentina (C.25.10.06); o que la escasez de compradores en la City se debe de nuevo a inversiones especulativas y el menor ahorro de los ingleses (C.7.6.07); inversamente, el excesivo gasto de las clases altas y medias provoca la caída de la deuda pública en Bolsa (C.20.8.07); indaga cómo se verá afectada Argentina en lo financiero por la guerra y lo transmite a sus lectores (LPB.3.1.15). El argumento de Maeztu en estos casos es el de J. M. Keynes (1936: 323-324): "Gran Bretaña, en los años de preguerra del siglo XX, proporciona un ejemplo de país en que las excesivas facilidades para los préstamos exteriores y la 
compra de propiedades en el extranjero impidieron a menudo la baja de la tasa de interés que era necesaria para asegurar ocupación plena en el interior".

En otros casos, son sus amigos de la City los que solicitan datos sobre la realidad española. Así ocurre con la súbita apreciación de la peseta a principios de 1906, desde el $75 \%$ de la paridad con el franco en enero hasta el $90 \%$ de mayo, que resultaba absolutamente inexplicable desde la interpretación monetarista simple dada la reducida variación de la circulación monetaria en tan poco tiempo (Maluquer de Motes, 1997: 20). Maeztu desconoce las razones y trasmite la consulta al corresponsal financiero del periódico en Madrid. No parece preocuparle su escaso conocimiento de las finanzas porque "lo principal es enseñar a discurrir a nuestro pueblo en materias financieras a fin de que no se deje desollar como en la época de la construcción de los ferrocarriles" (C.25.3.06). Días después se ha informado mejor. Parece que el alza se había debido a una gran entrada de capital extranjero y de los españoles residentes en América, y a la inversión de las Órdenes religiosas francesas en España.

"Hay gran interés en Inglaterra por la inversión en España, y aunque la subida del valor de la peseta parece un obstáculo no lo es, dado que se interpreta en medios financieros como señal de la buena marcha de la economía española. España se está recobrando rápidamente del colapso financiero acarreado por el crack bilbaino de 1901. La confianza en los negocios industriales y mineros renace. Raro es el día en que cronista no se encuentra en Londres algún español que se propone tender un ferrocarril, explotar alguna mina o estudiar los procedimientos que Inglaterra ha puesto en práctica para el mejoramiento de su ganadería, con objeto de implantarlos en España. Otros vienen en busca de capitales, que en Inglaterra no se muestran tan reacios como en España para los negocios industriales" (C.1.4.06)

La solicitud de créditos exige ciertos requisitos técnicos que Ramiro detalla. Bien sabía nuestro corresponsal de qué hablaba porque él mismo se había introducido en operaciones de inversión, como relata a su hermana María: “¿No te ha dicho mamá que tengo entre manos negocios muy gordos? Pues uno de ellos, el del salto del Ter, está ya aceptado por una casa inglesa y con lo que produzca hay ya lo bastante para que todos salgamos de apuros. Estos negocios míos son todos buenos y legítimos y sin riesgo alguno. Consisten, como ves, en vender asuntos españoles a compañías inglesas que por ser más ricas, pueden hacerlos prosperar, y en cobrar la comisión estipulada. Por primera vez en mi vida entreveo diáfana y clara la probabilidad de hacerme rico y ya sabes que no soy optimista" (ARM, 6.6.06). Otro ejemplo: "la cotización de la peseta sube por la confianza que la boda real da a los inversores ingleses" (C.19.5.06). Escribirá a Olariaga (1974: 51) que "ahora sí puedo asegurar que estoy capacitado para resolverle las dudas metódicas en el mundo de la economía, claro que sólo hablo de las dudas metódicas, que no son las más importantes" (25.05.14). Años después (1956), José Félix de Lequerica, un político y financiero bilbaíno, in- 
corpora la doctrina de Maeztu para interpretar la figura del empresario vizcaíno: la adquisición de riqueza como piedra de toque de la conducta personal.

Otra fuente que utiliza con profusión son las estadísticas publicadas por el Board of Trade: las compara con los datos de Estados Unidos cuya cosecha de maíz supera en valor a toda la producción agrícola e industrial inglesa (H.11.2.13). El censo industrial confirma el declive inglés pues si se repartiera su producto nacional sólo corresponderían a cada habitante 625 francos (NM.11.6.14). Publica datos sobre salarios, rentas y precios de alimentos en 1912. Le llama la atención el constante desequilibrio entre salarios y precios con considerable aumento del precio de las materias primas, y de artículos de primera necesidad (H.4.9.13). También acude a la prensa inglesa que, por ejemplo, da cuenta (C.14.4.05) del presupuesto de ese año, y apostilla Ramiro que en las islas pagan el doble de impuestos que en España. Describe el escándalo especulativo con las acciones de una empresa minera (oro) en Siberia (C.22.1.07). Aclara la caída de las acciones de compañías ferroviarias en New York, provocada por las maniobras del magnate E. Harriman. Anuncia la quiebra el Birkbeck Bank a causa de una errónea política de inversiones (NM.15.6.11). Asimismo la Cámara de Comercio de España en Londres, a través de E. Llanos (presidente) y R. Amigó (secretario), le suministran información sobre exportaciones españolas a Inglaterra (C.6.2.05); y sobre comercio de Inglaterra y Francia desde 1900 (C.20.11.05). Por último, se hace eco de las informaciones de The Economist, revista que sigue habitualmente. Así conocen sus lectores que la subida del precio del caucho por el desarrollo de la industria del automóvil provoca en Londres una intensa especulación; la revista desaconseja comprar, él lo ve como una locura que terminará en crack (H.10.5.10); el reportaje del semanario sobre la industria del norte de Italia puede ser modelo para España (H.21.5.10); también da a conocer a los exportadores españoles de productos agrícolas la existencia de El mercantil español, un periódico que se publica en Francfort (NM.2.7.14). Y dos días más tarde, critica la mala organización de la Exposición Española en Londres (H.4.7.14). Junto a la tristeza de la Exposición comenta el éxito del Suplemento extraordinario de The Times dedicado a España, aunque le entristece que el magnífico artículo de Flores de Lemus vaya marcado con las letras "Advt", es decir, de anuncio pagado. Mejores fueron las actuaciones del Orfeón Catalán en el Albert Hall, pero se pregunta por la ausencia de Casals (NM.5.17).

Como ya se indicó, Maeztu lee con avidez todo aquello que aporta sustancia a sus artículos. Así hace con el hacendista norteamericano E. R. Seligman del que reseña la traducción castellana de A. Posada de su libro La interpretación económica de la historia (NM.28.1.09); a Ramiro le interesa su Two Chapters on the Medieval Guilds of England (1887). Usa el libro de W. Sombart, Guerra y Capitalismo para probar que la guerra retrasa el desarrollo del capitalismo: "Esta verdad es tan evidente, que sería hasta ofensivo proclamarla si no hubiera 
millones de gentes cuyo credo político se funda en atribuir al capitalismo la función de "Deus ex machina" o de demonio inspirador de la totalidad de las instituciones sociales" (H.17.3.13). Al mismo tiempo, critica The rise of economic individualism, de $\mathrm{H}$. Robertson, a pesar de ser un ataque a las tesis de Weber que el mismo Maeztu había defendido (H.30.12.34). Conoce la teoría económica del crédito social de P. H. Douglas, que sigue la teoría del valor y la distribución de Böhm-Bawerk. Douglas es autor de Theory of Wages (1934), pionero de los estudios econométricos, es quizá más conocido por la fórmula Cobb-Douglas (1928) que mide la participación relativa de los factores productivos en el producto nacional. Recoge las prescripciones del economista sueco Gustav Cassel (1866-1945) en su Memorándum sobre los problemas monetarios del mundo a la Sociedad de Naciones que son: restauración del librecambio, trato comercial por igual con todos los países, demora de la deuda por indemnizaciones; añade Ramiro (C.4.10.20) que es lo que él viene diciendo desde 1918, lo cual sólo es cierto a medias. Su renombre crece tras la IGM al participar en las discusiones acerca de las indemnizaciones alemanas y de la restauración del patrón oro. Anti-keynesiano acérrimo, examina los posibles remedios contra el desempleo y rechaza los basados en aumentos directos del poder adquisitivo, en obras públicas o en aumento de los subsidios.

Tampoco podemos ignorar la influencia de Maeztu que conocía bien el problema a través de las estancias que en 1918 y 1919 realiza para su periódico en Alemania. Contra la intransigencia francesa Maeztu defiende una paz "moderada" (LPB.11.5.19), sin humillaciones ni cargas económicas que no pueden soportar, citando párrafos del libro de Keynes (C.1.7.20). Una paz basada en la venganza y el odio no haría sino acumular afanes de revancha en el bando vencido; y anota proféticamente: "lo que suele provocar una presión imperialista sobre el pueblo que la padece es una reacción de carácter nacionalista. Y esto es probablemente lo que provocará en Alemania" (LPB.18.5.19). No se puede dejar a Alemania desesperada y hambrienta en manos bolcheviques. Al menos, dice, los ingleses han comenzado a organizar su economía sin esperar las indemnizaciones alemanas que es lo que hace Francia (LPB.24.5.19). No parece descabellado pensar que estas opiniones influirían en las que se iba formando su amigo y paisano Olariaga y que llevará a la conferencia de Génova.

Maeztu afirmará que "el Banco de España ha hecho más daño que la guerra" (S.23.11.26), y aprovecha para pedir la creación de una Escuela de Banca (S.17.3.25). Afirma que Olariaga no se mete en especulaciones religiosas o morales. Únicamente establece la relación entre el capitalismo y la gran industria que Norteamérica habría recibido de Inglaterra, por ser este país el origen de la revolución industrial. Para Maeztu el capitalismo puro no triunfó en Inglaterra porque allí el puritanismo no predominó social ni políticamente, siendo Gran Bretaña una "transacción entre puritanos y cavaliers". Tema que continúa en el siguiente artículo de $\mathrm{El} \mathrm{Sol}$. 
Estos artículos deben ser puestos en relación con la serie que en 1915 había publicado Olariaga en la revista España titulados: "El Banco de España, plaga nacional", y la que publicará en 1916 en El Imparcial sobre "La economía española y la guerra". De Sánchez de Toca cita dos libros: Nuestro problema monetario: actuación y desarrollo del Banco de España (1913) y Organización bancaria del crédito industrial (1919). También recurre a los estudios de Fernández Díez en la Revista Nacional de Economía sobre la industria catalana (S.26.11.26). De este modo Ramiro fue mejorando su bagaje económico. Cuando publica Olariaga esos artículos Ortega preguntará a Maeztu si las opiniones de Olariaga sobre el Banco de España eran de fiar; es decir, si eran objetivas y desinteresadas. Maeztu le tranquilizó: "No puedo asegurar que tenga razón en todo lo que dice, pero sí que lo piensa honradamente". Ortega debió de quedar satisfecho ya que los publicó con la siguiente entradilla: "La serie de estudios que hoy comenzamos a publicar constituyen un ensayo de educación popular, según creemos que ésta debe hacerse, y según se hace en el país, maestro de estos usos necesarios a la democracia, Inglaterra: las cuestiones económicas y políticas son reducidas a términos claros y sencillos, comparando brevemente números y legislaciones, sin palabras violentas y excesivas, dando solo a los lemas aquella energía que facilita la comprensión en el pueblo" (Pérez de Armiñán, en Fuentes, 1999, VIII: 530). Era, a la letra, el lema de Maeztu aunque este vive en el presente, es un informador que toma los datos directamente de cualquier experto (sin citar fuentes, aporta datos de las reservas inglesas de carbón, hierro y acero; dice que un minero americano produce el doble que uno inglés) y no se preocupa demasiado por justificaciones históricas ni de fuentes.

\subsection{2. ¿A qué público quiere llegar Maeztu?}

Un rápido repaso por los medios en los que habitualmente publica sus artículos, nos muestra su inclinación por los periódicos de gran difusión. Escribe en La Correspondencia, el periódico de mayor tirada del país (100.000 ejemplares y cinco ediciones diarias), en los que sus artículos y telegramas llenaban a veces tres largas columnas en la primera página. Salvo el maurista El Mundo, de corta duración, que llegó a tirar el doble, no había medio más seguido en España que La Correspondencia. Ramiro publicó allí en dos periodos (1905-09 y 191620), con un intervalo de siete años (1909-16) en el que se dedicó a El Heraldo, del liberal Canalejas. Pomposamente anuncia Ramiro en 1909 que deja La Correspondencia para colaborar en la obra de "organizar las izquierdas de la sociedad española con mi pluma de periodista y mi cerebro de vulgarizador" (C.10.12.09). Su primer artículo allí lleva el título de "Las ideas liberales". Ramiro provocó con sus crónicas una sacudida en la aletargada sociedad española. La revista España publica que "la España contemporánea ha tenido en Maeztu el más poderoso transmisor de novedades de la inteligencia y el conocimiento" 
(E.10.7.19). Además de su corta participación en El Sol de Ortega a partir de 1917, Ramiro colaboraba con La Prensa de Buenos Aires (el de mayor tirada del país) donde, con frecuencia, aprovecha materiales ya utilizados en otros artículos. No es, pues, de extrañar que los principales periódicos españoles establecieran corresponsalías a partir de 1905 en la capital británica a la vista del éxito de sus crónicas.

Ramiro se dirige a un público cultivado al que intenta transmitir las ideas del momento, y aclara que escribe para la burguesía comercial y las clases medias, no para obreros. A pesar de sus simpatías por un socialismo moderado, no llega a ser un pensador socialista, pero sí defensor de las clases medias profesionales y empresariales: "la verdad es que no se me había ocurrido dirigirme a ellos [a los obreros]. Soy un español de clase media que escribe principalmente para españoles de clase media, entre otras razones porque estoy convencido de que son la sal y el provenir de España" (SRD: 49, S.10.8.26). Tras anotar que "el intento precipitado de industrializar a España fracasó hace diez años, sobre todo por falta de conocimientos técnicos por parte de industriales improvisados" (NM.18.7.12), se plantea cómo movilizar a esa clase, si es necesario formando los técnicos necesarios.

$\mathrm{Su}$ correspondencia con Ortega ilustra que quiere influir en la opinión pública y no "hablar desde el Sinaí". Al contrario que otros escritores de su generación lo vemos desde su llegada a Madrid, colaborando especialmente en periódicos de gran tirada como El País. A partir de 1901 sus colaboraciones se concentran en cinco grandes medios: La Correspondencia, El Imparcial, Diario Universal, El Pueblo Vasco y España. De los 400 artículos que publica entre 1896 y 1903, los seis ahora mencionados reciben, respectivamente, 48, 33, 34, 46, 31 y 20. La mitad aproximadamente. De 1905 a 1920 escribe casi exclusivamente para grandes periódicos nacionales: C (1625), H (602), NM (476) y LPB (250). La situación es la misma de 1921 a 1936 respecto a S (404), LN (61) y ABC (283) a los que hay que añadir una mayor presencia en periódicos de provincias.

Es prensa que lee especialmente las clases medias profesionales y empresariales que constituyen el público favorito de Maeztu. Llama a estas clases, "capitalistas productoras", "mercantiles" y "burguesas". Desde Inglaterra, donde le lleva el temor ante la campaña proteccionista de Chamberlain (C.5.1.05), se dirige a exportadores, inversores, industriales, profesores e ingenieros, de los que recibe abundante correspondencia que inserta en sus artículos. Araquistaín nos cuenta que sus lectores son la clase media (H.10.6.12), a Ortega dice que "voy llenando de ideas socialistas las cabezas burguesas de mis lectores" (RO: $122 ; 10.9 .08)$.

Nuestro hombre hace suyos los sueños de una burguesía que pretendía una revolución desde arriba, empeño que se diluye con la I Guerra Mundial. Cuando 
Olariaga llega a Londres poco queda del Maeztu que fustigaba a la burguesía desde posiciones anarquistas y socialistas condenándola por su incapacidad para solucionar los problemas españoles. Ahora la ve como la base de progreso para sacar a España de su marasmo. La burguesía regeneracionista se vuelve a posturas más conservadora, camino en el que le va a seguir Maeztu (Santervás, 1987: 78). Pero, frente al de Costa, su regeneracionismo carece de elaboración científica: desprecia "el arte por el arte" que no sirva para la transformación inmediata de la realidad o para "acrecentar la fortuna". Con tan escasa preparación sorprende que Maeztu se convierta en asesor de la burguesía en materias financieras y dé noticia de las cotizaciones de bolsa: así, advierte que son "poco rentables" las acciones de las minas de Transvaal, "asunto que afecta a muchos españoles", que compraron caro; desaconseja invertir en valores rusos por la inestabilidad del país (C.30.3.06). Fustiga a los empresarios españoles para que impidan que las empresas extranjeras disfruten en España de una "situación de privilegio por el miedo del Estado a las reclamaciones diplomáticas". Por razones económicas rehúsa la intervención militar en Marruecos: los más interesados son un grupo de financieros franceses que tratan de ganar el apoyo de la industria catalana para que exploten las concesiones del Marruecos francés (C.5.09.08).

A partir de un determinado momento parece advertirse una deriva progresiva en el lector que busca Maeztu. Son los años en torno a la I Guerra Mundial cuando comienza a advertirse su interés por el pensamiento weberiano y la incipiente tecnocracia. Maeztu dice a su hermana María haber "llegado ya a una solución definitiva y que significa un avance sobre el actual pensamiento europeo", porque tal carrera "está en el interés de la clase burocrática y no en el de la clase capitalista". Para él, "eso implica el reconocimiento de la clase burocrática, como clase aparte de la capitalista, de la proletaria y de la agrícola. Pero este reconocimiento de la burocracia entraña la revisión de todos los principios" (ARM, 23.3.13). Maeztu apunta al movimiento tecnocrático que pronto aparece en los Estados Unidos y que en la España de los años 60 tendrá una versión revisada del modelo, a partir de las intuiciones de Maeztu. Años después, volverá sobre lo mismo cuando explica a María sus teoría pedagógicas, que sustancian en "mostrar los caminos técnicos para que el alumno pueda contribuir a la conservación y el aumento de los valores" (ARM, 19.1.17).

El examen detallado rebate la imagen del Maeztu socialista, luego liberal, para acabar reaccionario. El hecho es que desde 1900 ya escribe en un medio conservador como es La Correspondencia y que en 1901 la mayor parte de sus artículos se publican allí y en El Imparcial. Este fenómeno de simultanear una publicación conservadora y una liberal se repite posteriormente con Nuevo Mundo y La Correspondencia. Tomando los 22 años centrales de su actividad hemos intentado desglosar sus artículos en función de la ideología del medio donde se publica. Eso nos da un 67 artículos (un $2 \%$ del total) en prensa de 
izquierdas, socialistas o radicales (El País, Germinal, El Socialista, Lucha de clases); 1516 artículos (un $32 \%$ ) en prensa liberal (Nuevo Mundo, 476; El Sol, 404; Heraldo, 202, El Imparcial, 34); y 2144 en prensa conservadora (un $45 \%$ ) (La Correspondencia, 1738; ABC, 283; Ahora, 62; La Nación, 61). No hemos incluido ahí, al haber muchas refundiciones, los publicados en España que era la revista de los intelectuales izquierdistas, lo que aumentaría el porcentaje de prensa liberal. En resumen, sumadas las colaboraciones en medios de izquierdas y liberales no se alejan mucho de la cifra de los conservadores, y eso sin considerar el efecto distorsionador de los 1738 artículos de La Correspondencia, obligado por su corresponsalía.

\subsubsection{Clasificación cronológica de sus artículos}

Maeztu fue un periodista muy prolífico pero hay que hacer poco caso de las afirmaciones exageradas de su hermana María cuando habla de "centenares de volúmenes" o de los "13.000 artículos" que le atribuye. Según cálculos de Santervás (1987: 16-20) la cifra no llega a los 5.000, 4.776 para ser precisos. Repartidos por periodos de tiempo de este modo: 490 (9\%) en 1896-1904; 3137 (65\%) en 1905-1920); y 1150 (24\%) en 1921-1936). Los años de mayor producción son los inmediatos a su llegada a Londres: el máximo en 1905 (315), luego se mantiene en torno a los 275 hasta 1910 , y ya la media de 1910-1920 no pasa de 150 artículos anuales. Claro que esto plantea un problema de difícil solución ya que es frecuente que un mismo artículo sea publicado, con leves modificaciones, en varios medios; esto es especialmente claro en la duplicidad que mantiene durante toda su carrera entre la prensa española y el periódico $L a$ Prensa de Buenos Aires. La mayor parte de los artículos del diario bonaerense son reproducciones de los que escribe en medios españoles; lo mismo ocurre con los ingleses en The New Age, publicados todos ellos en España también.

El rastreo de sus artículos nos da una fotografía bastante precisa de la vida maeztuana. Los primeros años (1897-1904) son de tanteo, con traducciones (Wells, Suderman), novelas, poesías, y viajes periodísticos (Bilbao, Jerez, Reus) que le restan tiempo para su labor de articulista. En 1905 se dedica por completo a La Correspondencia. Es el primer y único corresponsal en Londres. Devora libros y periódicos para tener bien enterados a sus lectores. Desde 1909 cuando prometiera a Ortega "estudiar" su producción disminuye. Viaja a París (1909), Italia (1909-1910), España (viajes cortos cada año), y sobre todo Alemania (seis meses en 1911, tres en 1912 y en 1913, cinco en 1914). Los años de la guerra mundial se prodiga en refundiciones de artículos, a veces publicados en tres medios. Realiza largas estancias en el frente británico. En 1920 regresa definitivamente a España. Embajador en Argentina desde 1928 no retoma su labor periodística hasta 1930 .

Otro interesante es la progresiva reducción del tamaño de sus artículos. La 
extensión de los de $E l$ Sol y $A B C$ es la mitad que los anteriores de La Correspondencia, el Heraldo y Nuevo Mundo. Esto se explica por la presencia de un nuevo estilo, más preciso y exigente, en el periodismo español.

\subsubsection{Temas que aborda en sus artículos}

Hay varios problemas cuando se intenta sistematizar los miles de artículos que Maeztu publicó. En primer lugar, su tono periodístico, mezclando en ocasiones referencias a dos o tres temas distintos, hace difícil su adscripción a un tema específico. Conviene recordar que vive de escribir en prensa y eso le exige abordar los temas del día, sean estos los que sean. Esta taxonomía la ha realizado Pérez de Armiñán (1991) para los artículos de Olariaga. Luego está la variedad de medios para los que escribe simultáneamente, unos más cultos ( $E l$ Sol), otros populares (La Correspondencia de España), por no mencionar las versiones simultáneas que elabora para la prensa argentina. Esto difumina las líneas que señalan la evolución de su pensamiento: desde una postura formalmente socialista, más tarde corporativista, para acabar en el tradicionalismo. Ese rastreo del fondo de sus ideas se hace más fácil en intelectuales como Ortega o economistas como Olariaga. Y hay, también, un mayor tono pesimista de sus artículos a partir de su experiencia como embajador en Argentina (1928) y el desencanto tras la crisis de 1929. Es consciente del "problema económico y financiero universal", pero lo ve desde España como una cuestión de patriotismo económico (De Miguel, en Perdices, 2006: 397). No olvidemos que, por encima de todo, Maeztu es un periodista. Lo mismo cabría decir de la evolución en las fuentes que utiliza. El contraste es grande con Olariaga.

Hemos intentado sistematizar los artículos por temas a lo largo del tiempo. Los temas de sus artículos abarcan el amplio espectro de secciones de cualquier periódico: política nacional e internacional, vida social, arte y literatura, trabajo, economía, educación. El foco se reduce tras su estancia filosófica en Alemania (1911) concentrándose desde 1915 en los aspectos políticos, económicos y de organización social. Y a partir de su estancia en los Estados Unidos serán los económicos los que ocupen mayor espacio en sus artículos. Más en concreto. Entre 1897 y 1905 dominan temas como: anarquismo, anticlericalismo, marxismo y socialismo, el desarrollo industrial de Vizcaya, el regeneracionismo nietzscheano, y la influencia de Unamuno. En 1905-1907 presenta a Inglaterra y Japón como modelos regeneracionistas, junto a la superioridad anglosajona, la política española (Alfonso XIII) y la guerra de Marruecos. El periodo 19081910 está dominado por la polémica con Ortega y Gasset y la ruptura con Unamuno, los presupuestos de Lloyd George y su repercusión en las exportaciones españolas a ese país, y las elecciones inglesas de 1910. Entre 1911 y 1914 hay una idealización de Alemania y un rechazo del pragmatismo inglés. 1915-1918 está lleno de referencias al nuevo socialismo (The New Age), el gremialismo o 
socialismo arcaizante. Entre 1914 y 1919 se convierte en cronista de la I Guerra Mundial, hay una nueva idealización de Inglaterra en armas, Estados Unidos aparece como nuevo modelo regeneracionista, y la crisis española de 1917 tras la caída de Romanones. En 1919-1927, tras su regreso a España, es la revolución social y la guerra de Marruecos (1920-1923), sus relaciones con el Directorio (1923-1926), y aparece el capitalismo americano como modelo regeneracionista y el sentido reverencial del dinero, tras su viaje a Estados Unidos en 1925. En el último periodo (1928-1936) Maeztu es el caballero de la Hispanidad con la monarquía católica como modelo.

\section{CONCLUSIÓN}

La originalidad de Ramiro de Maeztu en la difusión de ideas económicas a través de artículos de prensa cobra relevancia si consideramos el humus doctrinal en el que se forma (la generación del 98) y el camino que siguieron la mayor parte de sus integrantes. Decepcionados por la dureza de la pelea en la arena de la opinión pública, la mayoría de ellos se fue replegando hacia el campo menos arriesgado de los centros académicos y la alta cultura. Ortega, Olariaga y Maeztu son la excepción, y los que darán lugar a una más fecunda producción. Primero en España, y más tarde en Londres, Maeztu entendió que la conformación de un nuevo espíritu nacional, alejado de las rémoras que lo estancaron durante siglos, pasaba por involucrarse en la difusión de ideas económicas a partir de medios accesibles a las clases medias, como eran los artículos de prensa, luego convertidos en libros.

La labor de Maeztu irá calando en nuestro país, permeando los centros de formación de ideas a partir de 1936, insertándose en la corriente tecnocrática de tanta fortuna posterior, hasta dar forma a un corpus doctrinal sobre el que el franquismo basará su desarrollo. Esta deriva posterior de sus ideas, a partir de su trágica muerte en 1936, se escapa al objeto y el ámbito cronológico de este artículo, pero la referencia a los escritos de Maeztu, a su sentido reverencial del dinero, a la unión de lo técnico y lo religioso (el nacional catolicismo), son pruebas del impacto que tuvieron sus escritos en la conformación de las ideas socioeconómicas vigentes en la vida española en los años del franquismo. Lo cual es más sorprendente si tenemos en cuenta que, como hemos descrito, fue un autodidacta en economía y, en opinión de Olariaga, que sí era economista además de periodista, sin formación asentada. 


\section{REFERENCIAS BIBLIOGRÁFICAS}

ALSINA, J. (2013). "Los intelectuales y el liderazgo político: Maeztu y la Dictadura de Primo de Rivera”, en La razón histórica, 20, pp. 4-33.

ARRESE, A. (2000). "El desencuentro entre Periodismo y Economía", en Revista Empresa y Humanismo, Vol. 2, № 2, págs. 309-335.

CEPEDA, I. (2003). El pensamiento monetario de Luis Olariaga. Madrid: Instituto de Estudios Fiscales.

COLANDER, D. C.; COATS, A. W. (eds.) (1989). The Spread of Economic Ideas. New York: Cambridge University Press.

FERNÁNDEZ, E. (1976). "Maeztu y el sentido reverencial del dinero en la vida norteamericana", en Revista de Estudios Hispánicos, X (3), pp. 323-43.

FERNÁNDEZ, S. (2008). "Economía y hombre. Luis Olariaga Pujana y la nueva orientación de la Política Social”, en La razón histórica, 5 (2), pp. 24-34.

FUENTES, F.; SÁNCHEZ, S. (2010). "Análisis del perfil emprendedor: una perspectiva de género", en Estudios de Economía Aplicada 28 (3), pp. 1-28.

FUENTES QUINTANA, E. (coord.) (1999). Economía y economistas españoles (9 vols.). Barcelona: Galaxia Gutenberg.

FUENTES QUINTANA, E. y COMÍN, F. (coord.) (2008). Economía y economistas españoles en la Guerra Civil (2 vols.). Barcelona: Galaxia Gutenberg.

GAVIN, Neil T. (ed.) (1998). The Economy, Media and Public Knowledge. Londres: Leicester University Press.

GERSCHENKRON, A. (1970). Atraso económico e industrialización. Barcelona: Ariel.

GONZÁLEZ CUEVAS, P. C. (2003). Maeztu. Biografía de un nacionalista español. Madrid: Marcial Pons.

GONZÁLEZ, J.A.; ROBLES, A. (2000). "El intelectual entre dos siglos: profetismo, compromiso y profesionalidad”. En González, J.A. y Robles, A. (eds.): Intelectuales y ciencias sociales en la crisis de fin de siglo (pp. 7-8). Barcelona: Anthropos y Diputación provincial de Granada.

HALL, P. A. (1989). The Political Power of Economic Ideas: Keynesianism across Nations. Princeton: Princeton University Press.

KEYNES, J. M. (1936). Teoría general de la ocupación, el interés y el dinero. México: FCE.

MAEZTU, R. (1957). El sentido reverencial del dinero. Madrid: Editora Nacional.

MAEZTU, R. (1962). Autobiografía. Madrid: Editora Nacional.

MALUQUER DE MOTES, J. (1997). "Los economistas españoles ante la crisis del 98", en Revista de Historia Industrial, 12, pp. 11-39.

MARRERO, V. (1955). Maeztu. Madrid: Rialp.

MARRERO, V. (com.) (1974). Obra de Ramiro de Maeztu. Madrid: Editora Nacional.

MIGUEL, A. de (2006). "La industrialización vasca en la literatura". En Perdices, L. y Santos, M. (eds.): Economía y literatura, pp. 389-409.

OLARIAGA, L. (1974). "Cómo era y pensaba Ramiro de Maeztu en su etapa de Inglaterra". En V.V. A.A., En torno a Ramiro de Maeztu (pp. 45-61). Vitoria: Caja de Ahorros Municipal. 
OLARIAGA, L. (1992). Escritos de reforma, Madrid: Bosch (introducción de J. Velarde).

ORTEGA Y GASSET, J. (1974), Epistolario, Madrid: Revista de Occidente.

PÉREZ DE ARMIÑÁN, M. (1991). Problemas geo-políticos, económicos y sociales en la labor periodística del profesor Olariaga. Madrid: Instituto de Estudios Fiscales (prólogo de J. Velarde).

PERDICES, L.; SANTOS, M. (coord.) (2006). Economía y literatura. Madrid: Ecobook.

SANTERVÁS, A. R. (1987). La etapa inglesa de Ramiro de Maeztu. Tesis doctoral inédita.

SEAMAN, B. (2009). "Cultural Economics: The State of the Art and Perspectives", en Estudios de Economía Aplicada 27 (1), pp. 7-32.

TULLOCK, G. (1976). El cálculo del consenso: fundamentos lógicos de la democracia constitucional. Madrid: Espasa-Calpe.

VELARDE, J. (1968). Política económica de la Dictadura. Madrid: Guadiana.

VILLACAÑAS, J. L. (2000). Ramiro de Maeztu y el ideal de la burguesía en España. Madrid: Espasa-Calpe.

ZARATIEGUI, J. (1996). Caballeros y empresarios. El hombre de negocios victoriano. Madrid: Rialp.

ZARATIEGUI, J. (2006). "El periodismo económico de Ramiro de Maeztu". En L. Perdices y M. Santos (ed.), Economía y literatura (pp. 433-490). Madrid: Ecobook.

ZULETA, E. (2000). "Maeztu, Estados Unidos y el dinero”, en Razón Española, 99, pp. 7-17.

\section{Abreviaturas Utilizadas (revistas y periódicos, libros, archivos utilizados):}

ABC. ABC.

AE. Acción Española.

AEA. Alma Española.

ARM. Archivo Ramiro de Maeztu (correspondencia con su hermana María).

C. La Correspondencia de España.

E. España.

H. Heraldo de Madrid.

HOE. Hacia otra España.

LN. La Nación (Madrid).

LPB. La Prensa (Buenos Aires).

NM. Nuevo Mundo.

RO. Revista de Occidente.

S. El Sol.

SRD. El sentido reverencial del dinero. 